\title{
Species concept and morphological differentiation of strains traditionally assigned to Micrasterias truncata
}

\author{
Katarína Nemjová, * Jiří Neustupa, Jan Št'astný, Pavel Škaloud and Jana Veselá \\ Department of Botany, Faculty of Science, Charles University in Prague, Prague, Czech Republic
}

\section{SUMMARY}

The morphological and molecular differentiation of the Micrasterias truncata (Corda) ex Bréb species complex was investigated. In total, 17 strains traditionally assigned to $M$. truncata were isolated from different European localities (Czech Republic, southwest France, Ireland), and obtained from public culture collections. In addition, strains of the morphologically similar species, M. decemdentata (Nägeli) W. Archer and M. zeylanica F. E. Fritsch, were also included. Molecular phylogenetic analysis based on trnGucc intron sequences revealed five well supported clades. Two Australian strains assigned to M. truncata var. pusilla G. S. West formed a lineage sister to $M$. zeylanica. This was evident from a concatenated phylogeny based on small subunit rDNA and trnGucc intron sequences. The isolated position of these strains was also illustrated by parallel landmark-based geometric morphometric analysis of cell shapes. The strains NIES 783 and NIES 784 probably represent a separate species. Particular analysis, including additional strains, is needed to resolve the relationship inside this lineage. The second phylogenetic lineage, containing two strains of $M$. truncata var. semiradiata (Kützing) Wolle, was also different from other strains on the basis of morphometric data. We suggest recognizing this variety as a separate species, Micrasterias semiradiata L.A. Brébisson ex F. T. Kützing. The remaining three clades formed a firmly supported group of the 'core' $M$. truncata recognized by both molecular markers. However, neither any morphological, morphometric, nor geographical pattern was detected among members of these three clades. This pattern could be caused by a relatively recent origin of these lineages that may represent a sympatric, truly cryptic species. Strains attributable to traditional morphologically defined variety $M$. truncata var. neodamensis were nested within the 'core' $M$. truncata.

Key words: cryptic diversity, Desmidiales, geometric morphometrics Micrasterias truncata, small subunit rDNA, species concept, trnGucc intron.

\section{INTRODUCTION}

Desmids belong to the Zygnematophyceae, a class that represents the most diversified algal streptophycean lineage (Lewis \& McCourt 2004). They are known for their high morphological diversity and about 4000 species were described (Gontcharov 2008). Almost all of the species were traditionally defined on the basis of morphological characters. However, cross-breeding experiments illustrated that many traditional morphospecies, such as the Closterium ehrenbergii Meneghini ex Ralfs/ moniliferum Ehrenberg ex Ralfs complex (Denboh et al. 2003), or Micrasterias thomasiana W. Archer (Blackburn \& Tyler 1987), comprise several reproductively isolated possibly cryptic entities. Recently, desmid taxonomy has gained significant new insights through the application of molecular methods. Most of the traditional species-rich genera have been found to be polyphyletic (e.g. Cosmarium, Staurastrum or Euastrum) or paraphyletic (e.g. Micrasterias) (Gontcharov \& Melkonian 2005, 2008; Gontcharov 2008). A more robust outline of the phylogenetic relationships of the Desmidiales has begun to emerge on the basis of multigene molecular studies of the group (Gontcharov et al. 2004; Hall et al. 2008). Although many of the morphological generic characters were shown to be artificial, the validity of traditional desmidiacean species concepts is still puzzling. Denboh et al. (2003) illustrated considerable phylogenetic differentiation within a lineage corresponding to traditional Closterium ehrenbergii. However, the morphological differences among lineages within the traditional morphospecies were not evaluated. The only study that concentrated on molecular species concepts in the genus Micrasterias illustrated pseudocryptic diversity within the traditional species M. crux-melitensis Ralfs and M. radians W. B. Turner (Neustupa et al. 2010).

The genus Micrasterias is a widely distributed and well-known desmid genus, characterized by complex semicells divided into three lobes (Krieger 1939; Prescott et al. 1977; Růžička 1981). In the present study, we concentrated on the phylogenetic and morphological structures within the traditional species $M$. truncata.

\footnotetext{
*To whom correspondence should be addressed.

Email: nemjova@natur.cuni.cz

Communicating editor: O. De Clerck.

Received 24 September 2010; accepted 9 May 2011.

doi: 10.1111/j.1440-1835.2011.00619.x
} 
This species is one of the most frequently encountered desmids (Růžička 1981; Coesel \& Meesters 2007), and a number of traditional intraspecific taxa have been described. Their morphology differs from the type variety of the species, but, in many cases, intermediate forms have been reported (Prescott et al. 1977). In total, approximately 51 intraspecific taxa have been described (Guiry \& Guiry 2010). However, Růžička (1981), in his treatise of European desmids, accepted just five of them and concluded that many of the previously established varieties and forms may simply represent ecomorphs or dichotypic specimens. The species as a whole has a world-wide distribution, but some of the varieties apparently have restricted distribution, e.g. M. truncata var. pusilla in (sub-) tropical regions (Krieger 1939; Prescott et al. 1977). Several species, such as M. zeylanica and $M$. decemdentata, are morphologically similar to $M$. truncata and their phylogenetic and taxonomic relation is unclear (Tyler 1970; Růžička 1981).

In this study, we focused on infraspecific variation within this morphologically diverse species. We examined $17 \mathrm{M}$. truncata strains that were isolated from natural samples or acquired from public culture collections. The strains were morphologically evaluated according to the traditional criteria, and, if possible, identified to variety level. We used the polyphasic approach to assess phylogenetic diversity in morphologically defined $M$. truncata, and investigated gene sequence data of two independent molecular markers. The plastid encoded RNA-Gly transfer gene intron (trnG ${ }^{u c c}$ ) has previously been used in a phylogenetic study of the Micrasterias crux-melitensis/radians species complex (Neustupa et al. 2010), and shown to be useful for species delimitation. In addition, we used the small subunit (SSU) rDNA sequences to identify the phylogenetic relationships among $M$. truncata lineages and other related Micrasterias species. In parallel, morphological diversity was assessed using geometric morphometrics and scanning electron microscopy (SEM). Geometric morphometrics is a quantitative method for the evaluation of biological shapes, based on the Procrustes superimposition (Zelditch et al. 2004). It has recently been used in several studies investigating morphological variation in microalgae, e.g. diatoms (Rhode et al. 2001; Beszteri et al. 2005; Potapova \& Hamilton 2007), as well as in the genus Micrasterias (Neustupa \& Škaloud 2007; Neustupa et al. 2008, 2010). Summing up, we asked the following questions:

1 Do the clonal strains of $M$. truncata morphologically correspond to individual varieties described by traditional taxonomy (mostly on the basis of uncultured material)?

2 Is this traditionally defined species phylogenetically homogenous? If not, can the individual lineages be morphologically recognized?
3 Do they follow some obvious geographical distributional patterns?

\section{MATERIALS AND METHODS}

\section{Isolation and cultivation of strains, LM and SEM observations}

Strains of $M$. truncata were obtained from four culture collections (SVCK, CAUP - our own isolates, ASW and NIES), and complemented with single-cell isolates from different natural habitats (Table 1 ). The cultures for morphometric comparisons were initiated with 10-15 cells and grown for 6 weeks in $100 \mathrm{~mL}$ Erlenmeyer flasks in liquid oligotrophic medium used in the CAUP culture collection (for details see http://botany.natur. cuni.cz/algo/caup-media.html). Strains were maintained at temperatures of $20^{\circ} \mathrm{C}$ to $22^{\circ} \mathrm{C}$ and continuously illuminated at $40 \mu \mathrm{mol} \mathrm{m}{ }^{-2} \mathrm{~s}^{-1}$ from $18 \mathrm{~W}$ cool fluorescent tubes (Philips TLD 18W/33). Microphotographs were taken under an Olympus BX51 (Olympus, Tokyo, Japan) light microscope with an Olympus Z5060 camera. Projection of light microscopic images was made using the Deep Focus 3.0 module implemented in the QuickPHOTO CAMERA 2.3 software. For scanning electron microscopy (SEM) acetone-washed glass coverslips were placed on a heating block, and coated three times with a poly-L-lysine solution (1:10 in deionized water) to ensure appropriate adhesion of the cells. Then, a drop of the formaldehyde-fixed cell suspension was placed on the glass, transferred into 30\% acetone, and dehydrated by an acetone series. Subsequently, cells were dried to a critical-point with liquid $\mathrm{CO}_{2}$. Finally, they were sputter coated with gold and examined with a JEOL 6380 LV scanning electron microscope.

\section{Geometric morphometrics}

For each strain, we photographed 50 randomly chosen mature semicells. In total, 33 fixed or sliding landmarks were depicted on each semicell. In addition, landmarks were digitized on semicells of nine taxa illustrated in several authoritative taxonomic monographs (Krieger 1939; Růžička 1981). We included all the varieties of M. truncata recognized by Růžička (1981). In addition, we analyzed the type drawing of $M$. truncata var. pusilla, and figures of $M$. decemdentata and M. zeylanica (primarily for comparison with the NIES 783 and NIES 784 strains).

For most of the geometric morphometric analyses the TPS-series software (Rohlf 2008) was used. The positions of landmarks were digitized in TpsDig, ver. 2.12. The configurations of landmarks from 850 cells belonging to 17 strains were superimposed by the generalized Procrustes analysis (GPA) in TpsRelw, ver. 


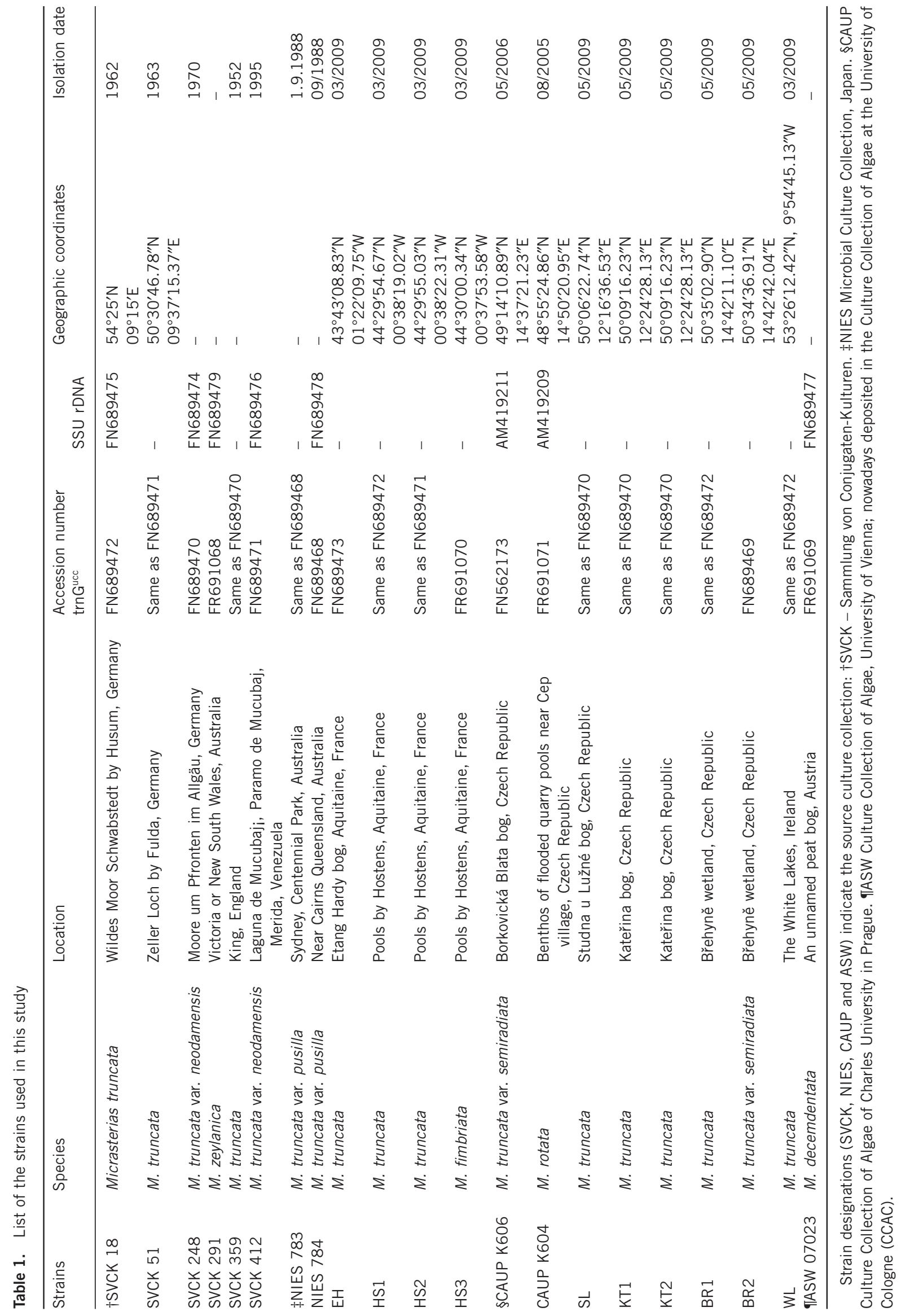


1.42. This widely used method standardizes the size and optimizes the rotation and translation of the objects (landmark configurations) so that the distances among corresponding landmarks are minimized (Bookstein 1991; Zelditch et al. 2004). The sliding landmarks are allowed to slide along the abscissa connecting adjacent landmarks in the course of GPA so that they can be used for delimitation of outlines (Zelditch et al. 2004; Mitteroecker \& Gunz 2009). Correlation between Procrustes and the Kendall tangent space distances was assessed using TpsSmall, ver. 1.20, to ensure that the variation in shape was small enough to allow subsequent statistical analyses (Zelditch et al. 2004). In the dataset of landmark configurations from $850 \mathrm{M}$. truncata semicells this correlation was very high $(r=0.999)$, so we proceeded with further analyses. The symmetrization of left and right semicell halves was conducted by the standard method of Klingenberg et al. (2002), in the same way as in previous geometric morphometric studies of Desmidiales (Neustupa \& Škaloud 2007; Neustupa et al. 2010).

The principal component analysis (PCA) of the entire set resulted in 62 axes describing the shape variation. The averages of the individual 17 strains were subjected to non-metric multidimensional scaling ordination analysis (NMDS), using the Euclidean distance matrix in PAST, ver. 1.90 (Hammer et al. 2001). The resulting two-dimensional ordination plot was used for graphical representation of the overall morphological relations among strains. The mean configurations of individual strains, and the comparative figures from the taxonomic monographs were used for the cluster analysis (using Ward's clustering method). The morphological separation between strains belonging to the $M$. truncata lineage and those of the $M$. truncata var. semiradiata lineage was tested by linear discrimination analysis (LDA) of the shape data depicted by the PC axes. The GPA-aligned shape data of the objects were regressed on the discriminant axis to illustrate the shapes features distinguishing these two lineages.

\section{DNA isolation, PCR reaction, sequencing}

Following disintegration of the mucilage enveloping the cells by ultrasonification, cell disintegration and DNA extraction was performed according to Neustupa et al. 2010 using the Invisorb Spin Plant Minikit (Invitek $\mathrm{GmbH}$, Berlin, Germany). The trnGucc and SSU rDNA markers were amplified in $20 \mu \mathrm{L}$ volumes of $13.9 \mu \mathrm{L}$ of sterile Mili-Q water, $2 \mu \mathrm{L}$ of $\mathrm{MgCl}_{2}(25 \mu \mathrm{M}), 2 \mu \mathrm{L}$ of polymerase chain reaction (PCR) Buffer $10 \times$ (Applied Biosystems, Life technologies, Carlsbad, CA, USA), 0.4 dNTP $(10 \mu \mathrm{M}), 0.25 \mu \mathrm{L}$ of each primer, $0.2 \mu \mathrm{L}$ of AmpliTaq polymerase $\left(5 \cup \mu \mathrm{L}^{-1}\right.$ ) and $1 \mu \mathrm{L}$ of DNA (not quantified). The trnGucc marker was amplified using the primers designed by Neustupa et al. (2010): trnG-
ucc-F 5'-AGCGGGTATAGTTTAGTGGT-3', and reverse trnG-ucc-R 5'-GGTAGCGGGAATCGAACCCGC-3'. The SSU rDNA gene was amplified using a combination of primers 18S-F (5'-AACCTGGTTGATCCTGCCAGT-3'; Katana et al. 2001) and $18 \mathrm{~L}$ (5'-CACCTACGGAAACC TTGTTACGACTT-3'; Hamby et al. 1988). The trnGucc and SSU rDNA markers were amplified in Touch Gene Gradient Cycler (Krackeler Scientific, Albany, NY, USA) and Mastercycler epgradientS (Eppendorf, Hamburg, Germany), starting with an initial denaturation at $94^{\circ} \mathrm{C}$ for $2 / 5 \mathrm{~min}$, followed by $40 / 35$ cycles of denaturing at $94^{\circ} \mathrm{C}$ for $1 \mathrm{~min}$, annealing at $62 / 56^{\circ} \mathrm{C}$ for $1 \mathrm{~min}$ and elongation at $72^{\circ} \mathrm{C}$ for $1.5 / 2.5 \mathrm{~min}$, and closed by a final extension at $72^{\circ} \mathrm{C}$ for $10 \mathrm{~min}$, respectively. Amplified DNA was quantified on $1 \%$ agarose gel stained by ethidium bromide, the DNA was stained with bromophenol blue loading dye and cleaned with the JetQuick PCR Purification Kit (Genomed, Löhne, Germany) according to manufacturer's protocol.

The PCR products were sequenced using either the same primers used for PCR (trnG ${ }^{\text {ucc }}$ ) or the set of nested standard primers (SSU rDNA; Katana et al. 2001) by Macrogen Inc., Seoul, Korea on an automatic 3730XL DNA sequencer using BigDye terminator cycling conditions. The SSU rDNA marker was amplified for selected strains after checking the molecular diversity in a more variable trnG ${ }^{\text {ucc }}$ marker. The sequences are available in the National Center for Biotechnology Information (NCBI) database (for accession numbers see Table 1).

\section{Sequence alignment and phylogenetic analyses}

Sequences were assembled and edited using Seqassem (Hepperle 2004). Subsequently, trnG ${ }^{\text {ucc }}$ sequences were aligned using the ClustalW algorithm implemented in the Mega 4.0 (Tamura et al. 2007) with default parameters using the IUB DNA weight matrix. After deleting identical sequences, the alignment stability was further assessed through comparison of ClustalW alignments produced under different gap opening/ extension penalties using SOAP v.1.2 alpha 4 (Löytynoja \& Milinkovitch 2001). The opening gap penalties were incrementally adjusted from 7 to 20 by steps of 2.5. The gap extension penalties were adjusted from 2 to 10 by steps of 1.5 . The final trnGucc alignment comprised 16 sequences of 727 characters.

Sequences of the SSU rDNA were aligned manually on the basis of their secondary structure (Denboh et al. 2001). The final alignment comprised 20 sequences of 1679 characters. Substitution models for both trnGucc and SSU rDNA alignments were estimated by Akaike Information Criterion (AIC) using the PAUP/MrMtGui v1.0b (Nylander 2004). The general reversible model for a proportion of invariable sites $(G T R+I)$ was selected as being the best for the trnGucc dataset, 
whereas for the analysis of SSU rDNA, the PAUP/ MrMtGui v1.0b selected the GTR + I + G model.

The phylogenetic trees were inferred with Bayesian inference (BI) using MrBayes version 3.1 (Huelsenbeck \& Ronquist 2001; Ronquist \& Huelsenbeck 2003). To better infer the phylogenetic relationships among species within the genus Micrasterias, the trnGucc sequences were concatenated with SSU rDNA data. The concatenated sequences originated from the same desmid strains, except in the case of $M$. fimbriata and Staurodesmus dickiei (Ralfs) S. Lillieroth, where the sequences of strain ASW 07026 (AJ428098.1) and HS3 (FR691070.1) were merged, respectively SVCK 38 (AJ428101.1) and ASW 07056 (FN562172.1). The concatenated dataset was divided into three partitions. The trnGucc partition was estimated using the selected model for trnGucc. The SSU rDNA dataset was further partitioned into stems and loops based on the secondary structure model published by Denboh et al. (2001). Different substitution models were selected for stem and loop regions. For the loop regions, a 4-state, single-nucleotide substitution model was selected; while for the paired stem regions, the doublet model (a 16-state RNA stem substitution model of Schöniger \& von Haeseler 1994) was selected (Verbruggen \& Theriot 2008). Two parallel runs were carried out for $5 \times 10^{6}$ (trnG ${ }^{\text {ucc }}$ ) and $10^{7}$ (concatenated dataset) generations, each with three heated and one cold chain. Trees and parameters were sampled every 100 generations. Convergence of the two cold chains was checked, and burn-in was set for the 'sumt' and 'sump' commands to a number that was $25 \%$ of the total number of trees.

Bootstrap analyses were performed under maximum likelihood (ML) and maximum parsimony (MP) criteria. The ML analyses were performed in PhyML 3.0 (Guindon \& Gascuel 2003) using the GTR + I + G model for concatenated dataset and GTR + I model for trnG ${ }^{\text {ucc }}$ dataset. The methods of subtree pruning re-grafting and the nearest neighbor interchange were used to improve individual topologies. Statistical support for resulting topologies was assessed by bootstrapping with 100 pseudo replicates of the original dataset. The MP analyses were conducted in the Mega 4.0 (Tamura et al. 2007). The MP bootstrap values of the consensus tree were inferred from 10000 replicates.

The obtained phylogenetic trees were displayed in FigTree v1.3.1 (Rambaut 2009) and Mega 4.0 (Tamura et al. 2007). Finally, the phylogenetic trees were graphically adjusted in Adobe Illustrator v 13.0.1.

\section{RESULTS}

\section{Morphology}

Most of the investigated strains (see Table 1), originally assigned as Micrasterias truncata, fitted well into the taxonomic definition of this broadly perceived species (Figs 1-13). However, there was a notable exception of the two Australian strains (NIES 783 and NIES 784) originally designated as $M$. truncata var. pusilla (Figs 14,15). These strains consistently produced semicells with compressed lateral lobes. These developed second order lobules, their upper margins were almost horizontal, and sometimes slightly undulated. The polar lobe was widely elliptical, with single spikes on both lateral margins. The dimensions of their cells were approximately $60-85 \mu \mathrm{m} \times 55-75 \mu \mathrm{m}$, i.e. smaller than in other $M$. truncata strains. These morphological features corresponded more to Micrasterias decemdentata (Fig. 16) or M. zeylanica (Fig. 17) (Krieger 1939; Tyler 1970; Prescott et al. 1977). M. truncata var. pusilla, described by West (1914), refers to cells with much wider lateral lobes, trapezoid-shaped polar lobes, and, typically, with a narrower subpolar angle (Krieger 1939; Prescott et al. 1977). Therefore, we decided to compare these NIES strains with cultures of $M$. decemdentata and $M$. zeylanica using molecular sequence data, as well as geometric morphometric comparisons to figures published in taxonomic monographs. The strains CAUP K606 and BR2 broadly corresponded to Micrasterias truncata var. semiradiata (Figs 18,19). This variety characterized dentate apices of lobes and lobules, by widely opened sinus and subpolar incisions, and by distinctly trapezoid-shaped polar lobes (Růžička 1981; Coesel \& Meesters 2007). Two other strains (SVCK 248, SVCK 412) were originally assigned to Micrasterias truncata var. neodamensis (A. Braun) W. Krieger (Figs 11,12). This variety is characteristic by shallow lobulation of their lateral lobes so that, in most cases, just the first order lobules are developed. In addition, the polar lobe is more or less rounded, bearing typically just a single spike at the lateral extremities. Both of these strains corresponded to this variety, and there were also additional strains (originally assigned as simply $M$. truncata - WL, SVCK 18 , SVCK 51) that were similar to $M$. truncata var. neodamensis also (Figs 9,10,13). The remaining strains seemed to correspond to the type variety of the species, Micrasterias truncata var. truncata (Figs 1-8). However, we still observed a considerable variation in some morphological features among the strains, such as in the angle of sinus and of subpolar incisions, and in width of the polar lobes. The cell walls of all the strains were invariably provided with the pore-linked mucilage extrusions (Figs 20-25).

\section{Geometric morphometrics}

We analyzed the shape distances among the investigated 17 strains acquired from the culture collections and isolated from nature. The non-metric multidimensional scaling ordination plot illustrated overall morphological separation of the NIES 783 and 784 strains 

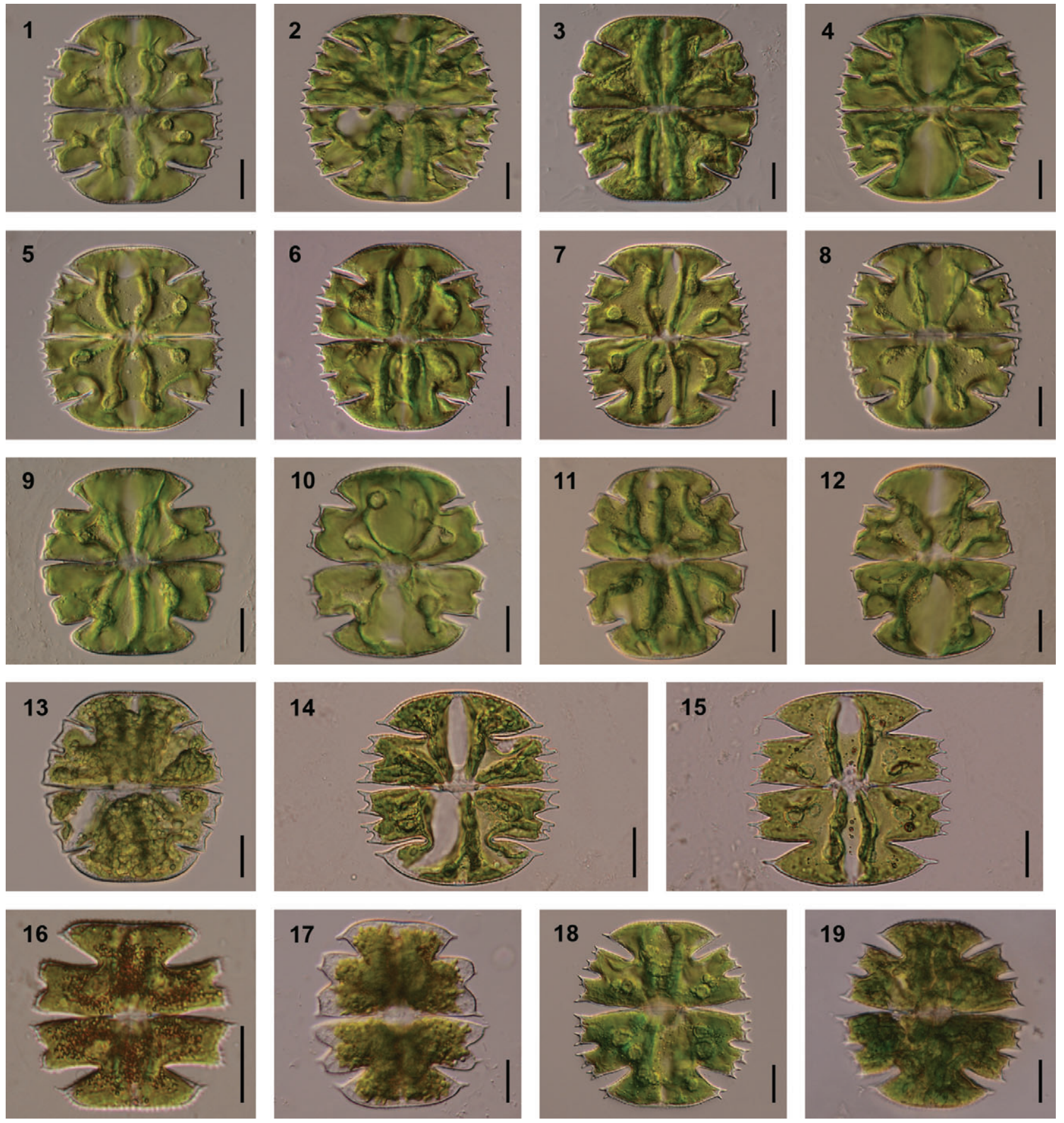

Figs 1-19. Light micrographs of investigated Micrasterias strains. 1-8. Micrasterias truncata var. truncata. 1. SVCK 359. 2. EH. 3. HS1. 4. HS2. 5. SL. 6. KT1. 7. KT2. 8. BR1. 9-13. Micrasterias truncata var. neodamensis. 9. SVCK 18. 10. SVCK 51. 11. SVCK 248. 12. SVCK 412. 13. WL. 14, 15. 'Micrasterias truncata var. pusilla'. 14. NIES 783. 15. NIES 784. 16. Micrasterias decemdentata ASW 07023. 17. Micrasterias zeylanica SVCK 291. 18, 19. Micrasterias truncata var. semiradiata. 18. CAUP K606. 19. BR2. Scale bar $=20 \mu \mathrm{m}$.

(Fig. 26). The strains corresponding to traditional $M$. truncata var. semiradiata (BR2, CAUP K606) were located on the other side of the ordination space. The rest of the strains formed a loose group located in the centre of the ordination space. Among them, the strains with reduced lobulation, broadly corresponding to $M$. truncata var. neodamensis (strains WL, SVCK 248, SVCK 412, SVCK 18, SVCK 51), were vaguely separated from the $M$. truncata var. truncata-like strains along the second ordination axis.

The cells of NIES 783 and NIES 784 proved to be similar to cells of M. decemdentata ASW 07023 and to 

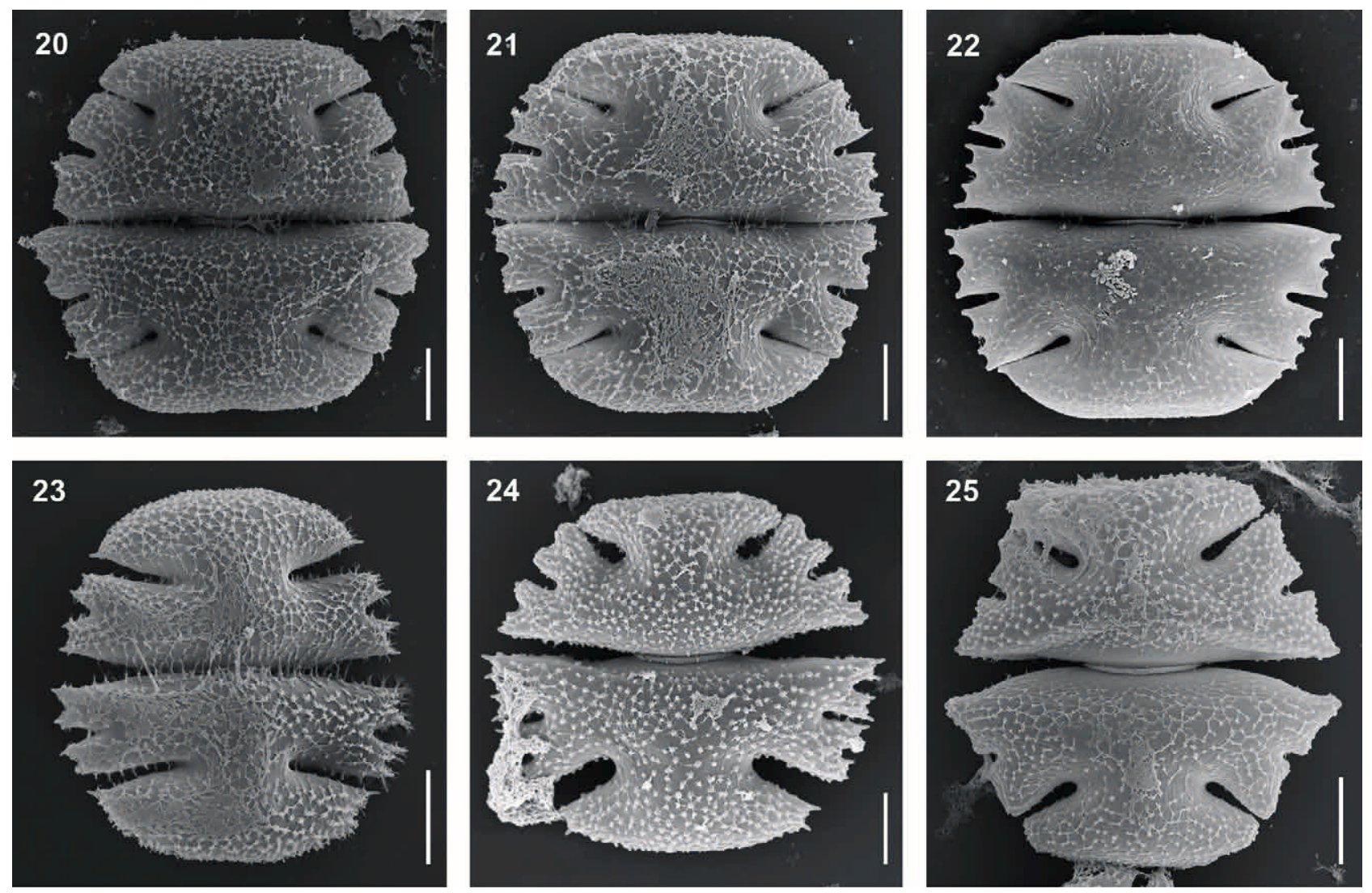

Figs 20-25. Scanning electron micrographs of investigated Micrasterias strains. 20-22. Micrasterias truncata var. truncata. 20. EH. 21. BR1. 22. KT1. 23. 'Micrasterias truncata var. pusilla' NIES 783. 24, 25. Micrasterias truncata var. semiradiata CAUP K606. Scale bar $=20 \mu \mathrm{m}$.

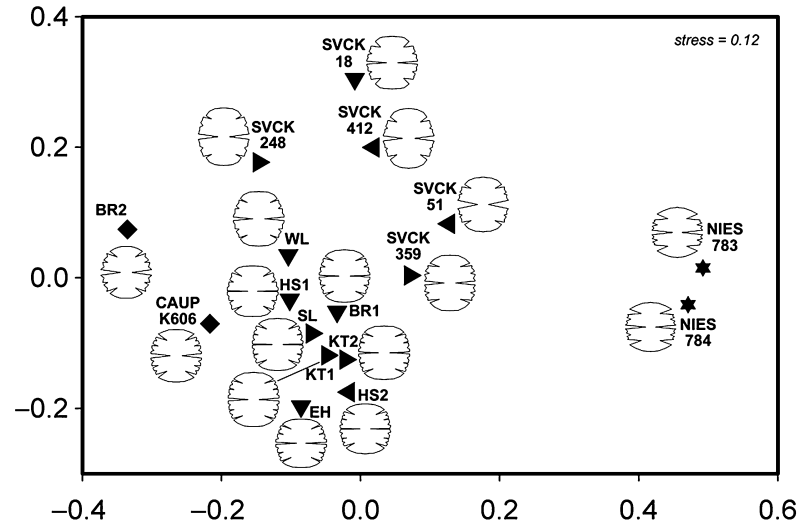

Fig. 26. The non-metric multidimensional scaling (NMDS) ordination diagram of the geometric morphometric data. The centroids of individual clonal populations are illustrated, and their shapes reconstructed from the landmark data. The symbols correspond to individual lineages as reconstructed by the phylogenetic analysis of trnG ${ }^{\text {ucc }}$ sequences. $M$. truncata var. semiradiata $(\diamond), M$. truncata var. pusilla $(\star)$, the core $M$. truncata lineages $(\nabla / 4 />)$.
M. zeylanica SVCK 291, as illustrated by the similarity dendrogram based on the landmark data (Fig. 27). In addition, they were also comparable to figures of these species from the literature, and to the shape of $M$. truncata var. bahusiensis Wittrock (Růžička 1981). The BR2 and CAUP K606 strains were most similar to published drawings of $M$. truncata var. semiradiata and M. truncata var. pusilla, respectively (Prescott et al. 1977). All the SVCK strains of M. truncata, together with the HS1 and WL isolates, clustered with M. truncata var. neodamensis. Conversely, isolates from the Czech Republic and southwest France were most similar to $M$. truncata var. truncata, and also to the two traditional varieties - $M$. truncata var. quadrata and $M$. truncata var. crenata (Ralfs) Grönblad.

Among the investigated strains, the shape separation of CAUP K606 and BR2, attributed to M. truncata var. semiradiata, from the rest of $M$. truncata isolates was not entirely apparent from the results of the ordination analyses (e.g. Fig. 26). Therefore, we proceeded with the discrimination analysis specifically evaluating their shape differences. This discrimination analysis was highly significant $\left(P<10^{-6}\right)$. In total, $99.6 \%$ of the semicells were correctly assigned into their phylogenetic 


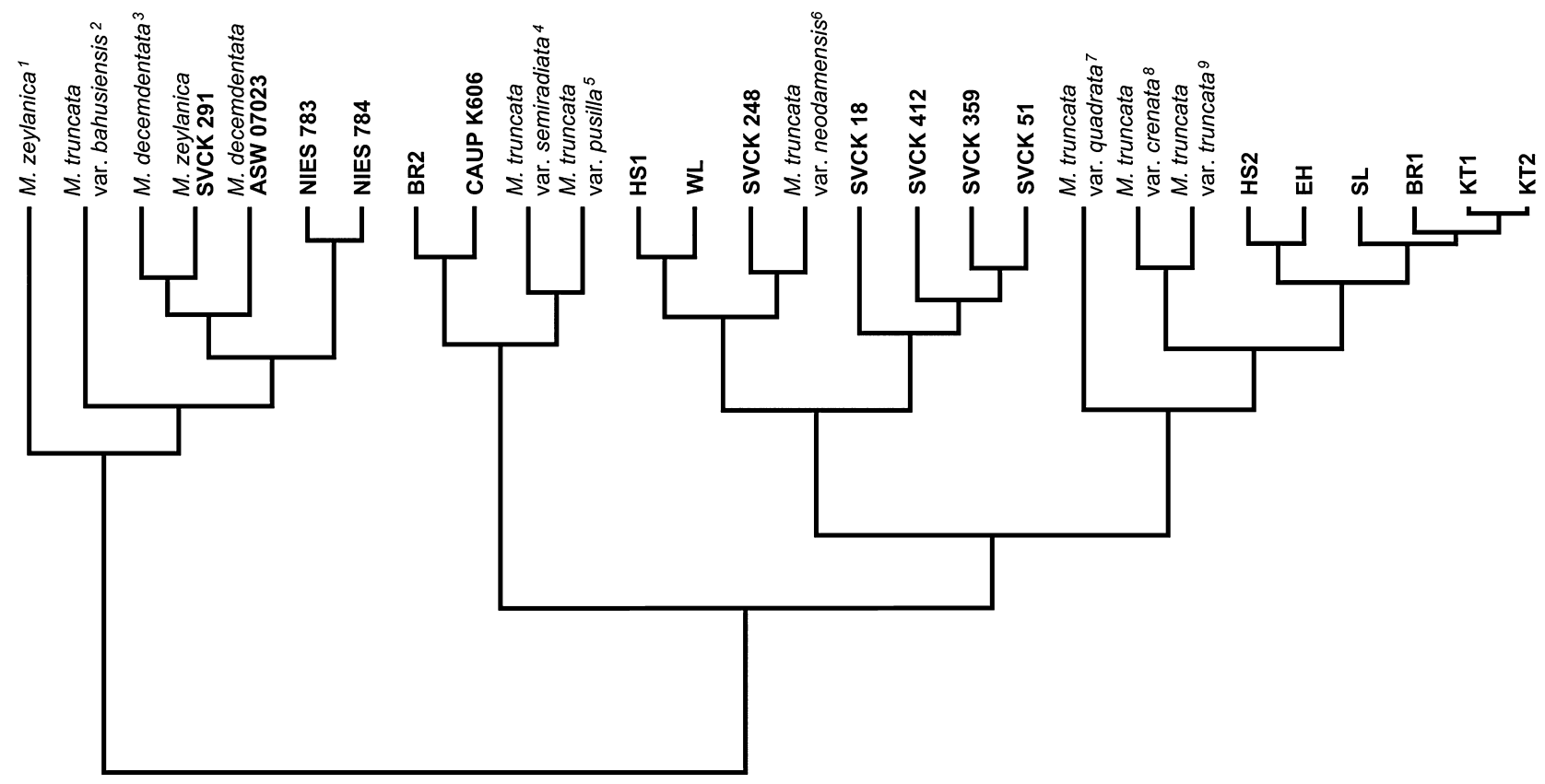

Fig. 27. The similarity dendrogram of centroids of investigated clonal populations (in bold) and published figures (in italic) based on the geometric morphometric data. The data for individual strains are included in Table 1 . The following figures from the literature were used: 1. Micrasterias zeylanica, Krieger (1939), Tf. 101, Figure 13; 2. M. truncata var. bahusiensis, Růžička (1981), Tf. 96, Figure 1; 3. M. decemdentata, Růžička (1981), Tf. 94, Figure 5; 4. M. truncata var. semiradiata, Růžička (1981), Tf. 94, Figure 15; 5. M. truncata var. pusilla, Krieger (1939), Tf. 102, Figure 9.; 6 M. truncata var. neodamensis, Krieger (1939), Tf. 103, Figure 8; 7. M. truncata var. quadrata, Růžička (1981), Tf. 96, Figure 16; 8. M. truncata var. crenata, Růžička (1981), Tf. 96, Figure 8; 9. M. truncata var. truncata, Růžička (1981), Tf. 95, Figure 1.

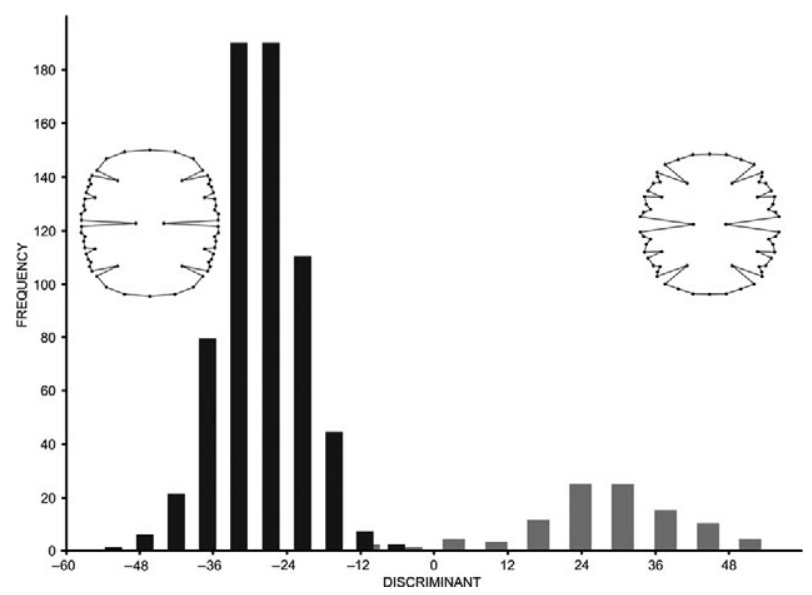

Fig. 28. The linear discrimination analysis of the geometric morphometric data distinguishing the Micrasterias truncata var. semiradiata (grey bars) from the core $M$. truncata (black bars). The shapes characteristic for marginal values of the discriminant axis were reconstructed from the landmark data.

groups, leaving only three out of the 750 objects misidentified by the discriminant function (Fig. 28). The shape characteristics were reconstructed for illustration of the morphological features that distinguish both lineages (Fig. 28). The M. truncata var. semiradiata cells differed from the other $M$. truncata strains primarily by their narrow, trapezoid-shaped polar lobes. In addition, the angle between polar and lateral lobes was clearly more open in $M$. truncata var. semiradiata strains than in the other investigated $M$. truncata cultures. Similarly, shape separation of traditional $M$. truncata var. truncata and $M$. truncata var. neodamensis was also tested. This linear discrimination analysis yielded a highly significant separation $\left(P<10^{-6}\right)$, and $98 \%$ of the semicells were correctly classified. In total, 13 out of the 650 objects were misidentified by the discriminant function.

\section{Molecular phylogeny}

The final trnGucc alignment contained 558 sites without polymorphism and 107 parsimony informative sites out of a total of 727 nucleotide characters. The GC content was rather low, only $31.7 \%$. The trnG ${ }^{\text {ucc }}$ based phylogeny of 17 investigated strains and related taxa revealed that organisms affiliated to $M$. truncata formed three well supported clades (Fig. 29). One of them consisted of NIES 783/784 strains with identical trnGucc sequences, closely related to the strain SVCK 291 of $M$. zeylanica. The second lineage contained two cultures with identical trnGucc sequences, corresponding to $M$. truncata var. semiradiata (CAUP K606 and BR2). The 


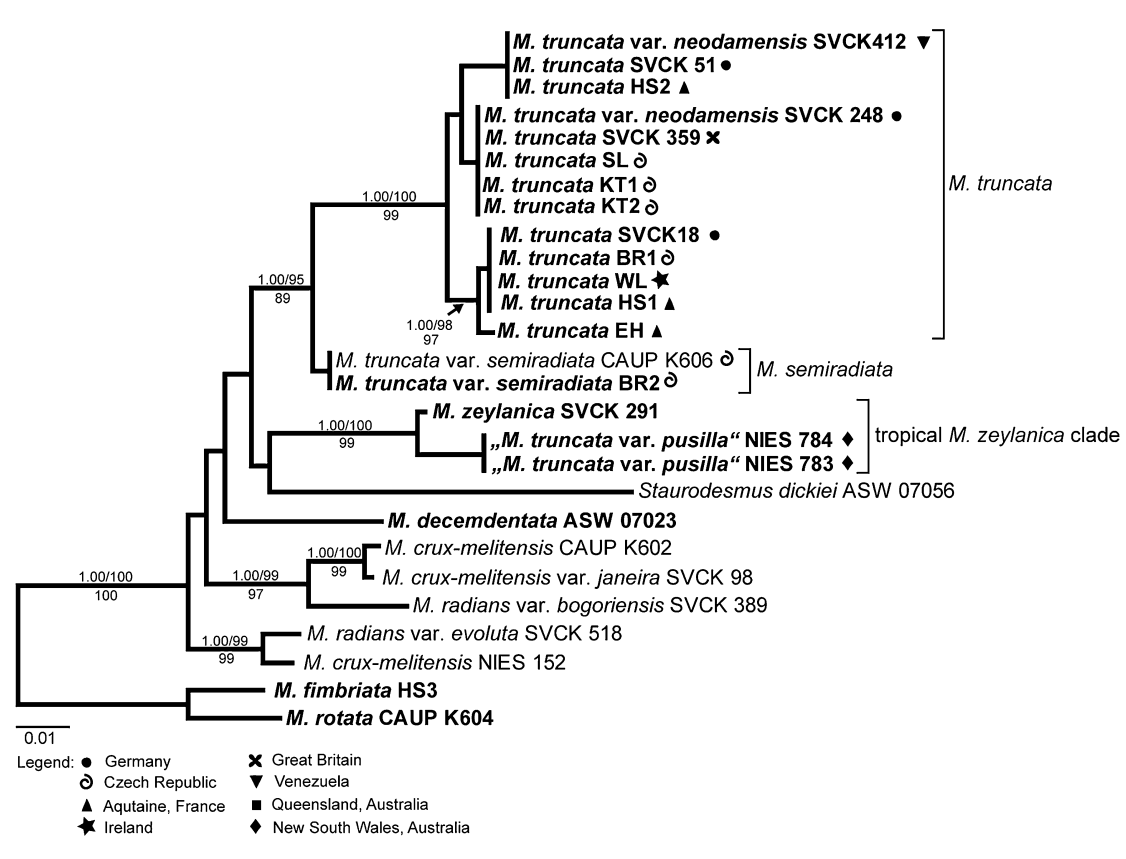

Fig. 29. Bayesian phylogenetic tree of Micrasterias truncata trnGucc sequences. The sequences of Micrasterias rotata and Micrasterias fimbriata were used as an outgroup. The scale bar shows the estimated number of substitutions per nucleotide. Names printed in bold represent sequences obtained in this study. The posterior probabilities lower then 0.70 and bootstrap support levels below $50 \%$ are omitted. The indicators of statistical significance are provided Bayesian posterior probability/maximum likelihood bootstrap support upon the branch and below the branch maximum parsimony bootstrap support. The geographic origin of investigated strains are provided. third highly supported clade included all the other investigated $M$. truncata strains. However, this clade was further divided into three clearly delimited subclades. The strains within each of these three subclades had identical sequences, with the single exception of the EH strain that differed by a single nucleotide substitution. The phylogenetic relationship among the three groups of the broad $M$. truncata clade remained unclear, due to a lack of bootstrap support for the sister position of groups containing SVCK 248 and SVCK 412 strains. The isolates belonging to these three groups showed neither geographical, nor morphological patterns. The strains originating from different European localities were morphologically indistinguishable, and even the single strain from Venezuela was identical to the other members of the phylogenetic group.

All available SSU rDNA sequences of related species (Neustupa et al. 2010) were used to infer broader phylogeny. The sequences of Euastrum humerosum Ralfs and Cosmarium depressum (Nägeli) P. Lundell were used as outgroups. The alignment contained 2123 sites without polymorphism and 283 variable sites out of a total 2406 sites. The GC content was higher than in trnGucc alignment, $44.5 \%$.

The phylogram (Fig. 30) demonstrated a better resolution of the relationships within the 'core' $M$. truncata clade, than the single trnGucc marker. The strain SVCK 248 was closely related to SVCK 18 , but not to the clade of SVCK 412. The phylogenetic tree also supported the sister position of $M$. truncata var. semiradiata to the $M$. truncata clade. The Bayesian analysis, as well as the maximum likelihood and maximum parsimony analyses, reconstructed the Australian ' $M$. truncata var. pusilla' as closely related to $M$. zeylanica, but not to the morphologically very similar M. decemdentata. The doublet-model based Bayesian phylogeny moderately resolved the positions within $M$. cruxmelitensis, M. radians, $M$. decemdentata and Staurodesmus dickiei; however, maximum likelihood and maximum parsimony does not support this branching order.

\section{DISCUSSION}

The 17 investigated strains appeared to be highly divergent, on the basis of morphometric, as well as molecular data. The Australian strains from the NIES culture collection (assigned to $M$. truncata var. pusilla) were obviously different from the rest of the $M$. truncata isolates. Their morphological differences were illustrated by the geometric morphometric analysis that placed these two strains outside of the true $M$. truncata cluster, apart from the published figures of $M$. truncata var. pusilla. The NIES strains, on the other hand, appeared to be more similar in shape to cultures and published figures of $M$. decemdentata and $M$. zeylanica. Indeed, the molecular phylogenetic analysis confirmed the position of these Australian strains to be different from other $M$. truncata isolates. Interestingly, they were closely related to M. zeylanica SVCK 291, also originating from Australia. Nevertheless, the European M. decemdentata (strain ASW 07023) was also morphologically very similar to NIES 783/784, but it appeared be only distantly related to these Australian strains. These results suggest that there may be a more complex phylogenetic structure among species of this morphological complex. Moreover, there have been several reports of morphotypes similar to the $M$. 
Fig. 30. The phylogenetic tree obtained through Bayesian analysis of concatenated data set of small subunit rDNA and trnGucc sequences. The sequences of Cosmarium depressum and Euastrum humerosum were used as an outgroup. The scale bar shows the number of substitutions per nucleotide. The posterior probabilities lower then 0.70 and bootstrap support levels below $50 \%$ are omitted. The indicators of statistical significance are provided upon the branch in following order: Bayesian posterior probability/maximum likelihood bootstrap support, below the branch is displayed maximum parsimony bootstrap support.

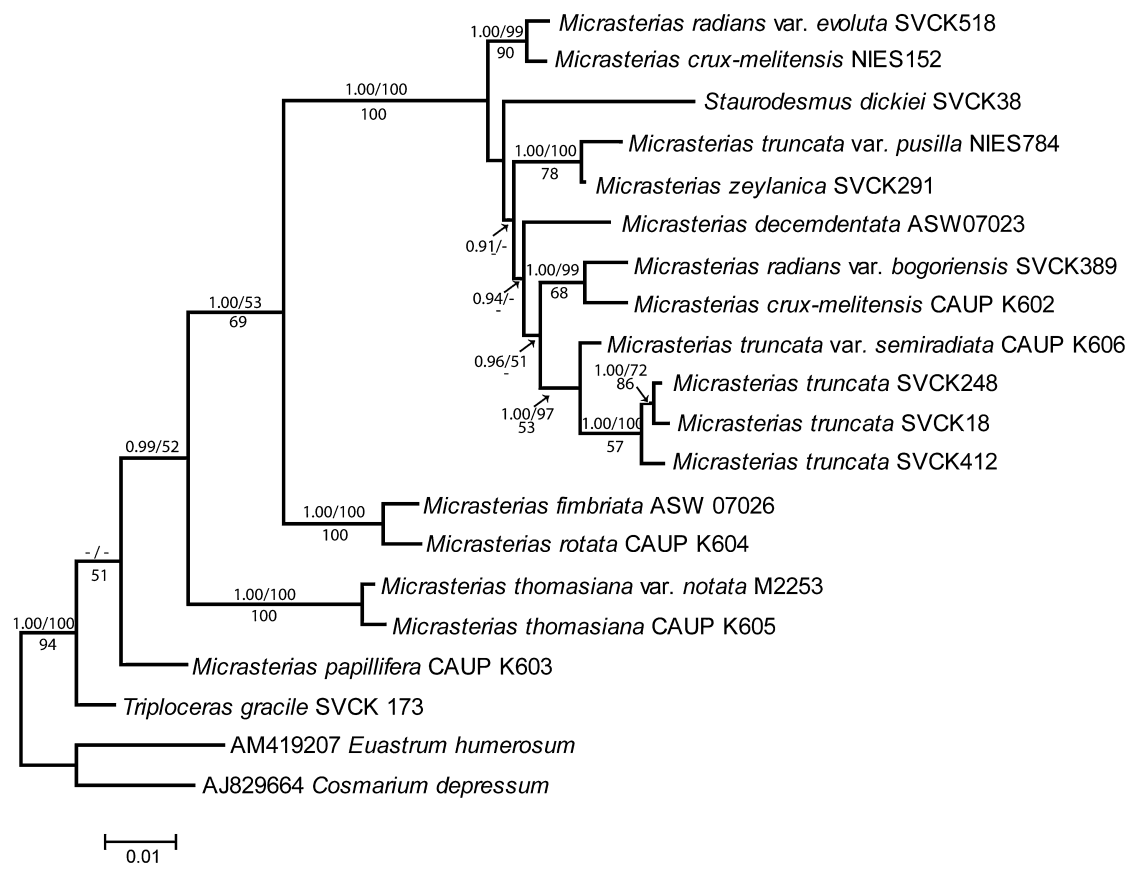

zeylanicaAIES 783/784 complex from Australia (Playfair 1908; Scott \& Prescott 1958; Tyler 1970), and the actual diversity of this lineage may be higher. However, this topic was beyond the scope of the present study, and future revision of this complex should be based on a comprehensive analysis of numerous Australian isolates. For now, we can conclude that the NIES 783 and NIES 784 strains, identified originally as $M$. truncata var. pusilla, probably represent a separate species.

There were several well supported phylogenetic lineages among the strains morphologically attributed to M. truncata. The two strains (BR2 and CAUP K606), identified morphologically as $M$. truncata var. semiradiata, formed an independent lineage in both phylogenetic trnG ucc and concatenated trees. Both these strains originated from localities within the Czech Republic, but this morphological variety has been reported from numerous localities across Europe (Kouwets 1999; Coesel \& Meesters 2007) and therefore is likely to be widely distributed. The morphological discrimination between $M$. truncata var. semiradiata cells and other $M$. truncata isolates was confirmed by the discrimination analysis of the geometric morphometric data. In fact, the high degree of morphological separation, as illustrated by the discrimination analysis, should make it possible to identify members of this lineage in natural samples using the traditional morphological criteria defining the original $M$. truncata var. semiradiata. The species name Micrasterias semiradiata was taxonomically described by Kützing (1849), and later re-classified as the variety of broadly perceived $M$. truncata by Wolle (1884). On the basis of phylogenetic and morphologic differences ascertained by our analyses, we propose that this taxon should once again be considered as a separate species, rather than a variety of M. truncata.

All the other investigated $M$. truncata strains belonged to the single well-supported lineage reconstructed by the trnGucc intron phylogenetic tree. Morphologically, the strains from SVCK collection, and the HS1 and WL isolates broadly corresponded to traditional M. truncata var. neodamensis according to their limited lobulation, and somewhat rounded polar lobes. The other strains isolated from the Czech Republic and from Aquitaine, France, were most similar to $M$. truncata var. truncata. These two varieties were also unambiguously discriminated on the basis of geometric morphometric data. However, the trnGucc molecular marker illustrated that the members of this lineage were further diversified into three subclades. Individual strains within these clades were phylogenetically homogenous in the trnG ${ }^{\text {ucc }}$ sequences irrespective of their geographic origin. Interestingly, the single strain from Venezuela (SVCK 412) also clustered into one of these three $M$. truncata clades, and did not differ from the temperate European isolates. In addition, members of these three clades were morphologically indistinguishable. They resembled either $M$. truncata var. neodamensis, or the type variety of the species, but this morphological disparity was not congruent with the molecular data. We propose that these lineages may represent a sympatric species, possibly of relatively recent origin. However, we were not able to find any morphological or biogeographical pattern that could possibly be used for their taxonomic delimitation. We cannot preclude that these lineages will be described as 
separate, truly cryptic species in the future. Their separate species status, however, will need to be confirmed by other features, including for instance, reproductive isolation and analyses of additional fast evolving molecular markers.

The present study demonstrated the usefulness of trnG ${ }^{\text {ucc }}$ marker for resolving intraspecific diversity within M. truncata species complex. By contrast, SSU rDNA seemed to be of limited use for determining relationships among closely related Micrasterias species, as rather low sequence divergence was detected. The noncoding intron sequences of plastid trnGucc gene have occasionally been used in phylogenetic studies of higher plants (e.g. Pedersen \& Hedenäs 2003; Shaw et al. 2005). However, in streptophyte algae it was used only recently by Neustupa et al. (2010), who inferred the species relationship in Micrasterias cruxmelitensis/ $M$. radians species complex. In that study, the plastid trnGucc phylogeny was shown to be highly congruent with the nuclear ITS2 rDNA phylogram. Because of some drawbacks that could dismiss the phylogenetic utility of multiple-copy nuclear sequences (Álvarez \& Wendel 2003), and a very high success in PCR amplification of the trnGucc intron, we recommend the use of this low-copy plastid marker for studies investigating phylogenetic differentiation of closely related desmid species.

Recently, taxonomic study of desmids has been significantly improved and advanced through the application of molecular methods that demonstrated the polyphyletic status of most traditional genera (see Introduction). At the species level, Neustupa et al. (2010) illustrated that the phylogenetic structure of Micrasteras crux-melitensis/M. radians complex reflected the morphological data to a large extent, and that, in some cases, the phylogenetic species lineages corresponded more accurately to traditional subspecific taxa. At the same time, the phylogenetic structure also reflected the geographic origin of strains (Neustupa et al. 2010). Similarly, in the present study we detected that traditional $M$. truncata var. semiradiata and M. truncata var. pusilla should be regarded as a separate species. However, the lack of any morphological or geographical signal in delimitation of three cryptic subclades of the $M$. truncata lineage has been revealed. The isolates belonging to these lineages resemble at least two traditional subspecific taxa, and they probably occur sympatrically across the European continent. Similar cryptic phylogenetic differentiation has also been ascertained in some other protistan groups, such as diatoms (Kooistra et al. 2008; QuijanoScheggia et al. 2009), foraminifers (Pawlowski et al. 2008) or green flagellates (Foulon et al. 2008). In most of these groups, such cryptic lineages have not been formalized as separate species, as yet. Fenchel and Finlay (2006) even suggested that the protistan species should, in general, be defined at higher phylogenetic levels encompassing mostly widely distributed lineages with ecological and phenotypic differentiation. We also do not suggest that the cryptic subclades of the $M$. truncata lineage should be described as separate taxa at this time. However, their existence illustrates that the traditional, well known and frequently encountered desmid morphospecies, such as $M$. truncata, may actually represent cryptic phylogenetic complexes.

This study demonstrated that geometric morphometric methods may be useful for taxonomic revisions of species as the majority of the desmid descriptions were based on the iconotypes. In addition, this approach was quite powerful to define the morphological discrimination features of the $M$. semiradiata and $M$. truncata lineages. Correct species concepts, and development of appropriate methods for species delimitation could be highly useful as the desmids diversity data have been frequently used in numerous ecological applications (Coesel 2003; Krasznai et al. 2008; Neustupa et al. 2009).

\section{ACKNOWLEDGMENTS}

We thank Monika Engels and Petra Wagner for kind provision of strains from the SVCK culture collection for this research. The study was supported by grant no. 206/09/0906 of the Czech Science Foundation, and by research project no. 35010 of the Charles University Grant Agency.

\section{REFERENCES}

Álvarez, I. and Wendel, J. F. 2003. Ribosomal ITS sequences and plant phylogenetic inference. Mol. Phylogenet. Evol. 29: 417-34.

Beszteri, B., Ács, É. and Medlin, L. 2005. Conventional and geometric morphometric studies of valve ultrastructural variation in two closely related Cyclotella species (Bacillariophyta). Eur. J. Phycol. 40: 89-103.

Blackburn, S. I. and Tyler, P. A. 1987. On the nature of eclectic species - a tiered approach to genetic compatibility in the desmid Micrasterias thomasiana. Eur. J. Phycol. 22: 277-98.

Bookstein, F. L. 1991. Morphometric Tools for Landmark Data: Geometry and Biology. Cambridge University Press, New York.

Coesel, P. F. M. 2003. Desmid flora data as a tool in conservation management of Dutch freshwater wetlands. Biologia 58: 717-22.

Coesel, P. F. M. and Meesters, K. J. 2007. Desmids of the Lowlands. Mesotaeniaceae and Desmidiaceae of the European Lowland. KNNV Publishing, Zeist.

Denboh, T., Hendrayanti, D. and Ichimura, T. 2001. Monophyly of the genus Closterium and the order Desmidiales 
(Charophyceae, Chlorophyta) inferred from nuclear small subunit rDNA data. J. Phycol. 37: 1063-72.

Denboh, T., Ichimura, T., Hendrayanti, D. and Coleman, A. W. 2003. Closterium moniliferum-ehrenbergii (Charophyceae, Chlorophyta) species complex viewed from the 1506 group I intron and ITS2 of nuclear rDNA. J. Phycol. 39: 96077.

Fenchel, T. and Finlay, B. J. 2006. The diversity of microbes: resurgence of the phenotype. Phil. Trans. Biol. Sci. 361: 1965-73.

Foulon, E., Not, F., Jalabert, F., Cariou, T., Massana, R. and Simon, N. 2008. Ecological niche partitioning in the picoplanctonic green alga Micromonas pusilla: evidence from environmental surveys using phylogenetic probes. Environ. Microbiol. 10: 2433-43.

Gontcharov, A. A. 2008. Phylogeny and classification of Zygnematophyceae (Streptophyta): current state of affairs. Fottea 8: 87-104.

Gontcharov, A. A. and Melkonian, M. 2005. Molecular phylogeny of Staurastrum Meyen ex Ralfs and related genera (Zygnematophyceae, Streptophyta) based on coding and noncoding rDNA sequence comparisons. J. Phycol. 41: 887-99.

Gontcharov, A. A. and Melkonian, M. 2008. In search of monophyletic taxa in the family Desmidiaceae (Zygnematophyceae, Viridiplantae): the genus Cosmarium. Am. J. Bot. 95: 1079-95.

Gontcharov, A. A., Marin, B. and Melkonian, M. 2004. Are combined analyses better than single gene phylogenies? A case study using SSU rDNA and rbcL sequence comparisons in the Zygnematophyceae (Streptophyta). Mol. Biol. Evol. 21: 612-24.

Guindon, S. and Gascuel, O. 2003. A simple, fast and accurate algorithm to estimate large phylogenies by maximum likelihood. Syst. Biol. 52: 696-704.

Guiry, M. D. and Guiry, G. M. 2010. AlgaeBase. World-wide electronic publication, National University of Ireland, Galway [cited 23 February 2010]. Available from:http:// www.algaebase.org/.

Hall, J. D., Karol, K. G., McCourt, R. M. and Delwiche, C. F. 2008. Phylogeny of the conjugating green algae based on chloroplast and mitochondrial nucleotide sequence data. J. Phycol. 44: 467-77.

Hamby, R. K., Sims, L., Issel, L. and Zimmer, E. 1988. Direct ribosomal RNA sequencing: optimization of extraction and sequencing methods for work with higher plants. Plant Mol. Biol. Rep. 6: 175-92.

Hammer, O., Harper, D. A. T. and Ryan, P. D. 2001. PAST: palaeontological statistics software package for education and data analysis. Palaeontol. Electronica 4: 1-9.

Hepperle, D. 2004. SeqAssem (C. A sequence analysis tool, contig assembler and trace data visualisation tool for molecular sequences. Available from: http://www. sequentix.de/software_seqassem.php.

Huelsenbeck, J. P. and Ronquist, F. 2001. MRBAYES: Bayesian inference of phylogeny. Bioinformatics 17: 754-5.
Katana, A., Kwiatowski, J., Spalik, K. and Zakrys, B. 2001. Phylogenetic position of Koliella (Chlorophyta) as inferred from nuclear and chloroplast small subunit rDNA. J. Phycol. 37: 443-51.

Klingenberg, C. P., Barluenga, M. and Meyer, A. 2002. Shape analysis of symmetric structures: quantifying variation among individuals and asymmetry. Evolution 56: 190920.

Kooistra, W. H. C. F., Sarno, D., Balzano, S., Gu, H., Andersen, R. A. and Zingone, A. 2008. Global diversity and biogeography of Skeletoma species (Bacillariophyta). Protist 159: 177-93.

Kouwets, F. A. C. 1999. A check-list of desmids (Chlorophyta, Zygnemaphycea) of France. Patrimoines Natureles 41: 1-148.

Krasznai, E., Fehér, G., Borisc, G., Várbíró, G., Grigorszki, I. and Tóthmérész, B. 2008. Use of desmids to assess the natural conservation value of a Hungarian oxbow (MalomTisza, NE-Hungary). Biologia 63: 928-35.

Krieger, W. 1939. Die Desmidiaceen Europas mit Berücksichtigung der aussereuropäischen Arten, Dr. L. Rabenhorst's Kryptogamen-Flora von Deutschland, Österreich und der Schweiz. Band 13, Abteilung 1. Teil 2, Lieferung 1. Akademische Verlagsgeselschaft M.B.H, Leipzig.

Kützing, F. T. 1849. Species Algarum. F. A. Brockhaus, Leipzig.

Lewis, L. A. and McCourt, R. M. 2004. Green algae and the origin of land plants. Am. J. Bot. 91: 1535-56.

Löytynoja, A. and Milinkovitch, M. C. 2001. SOAP, cleaning multiple alignments from unstable blocks. Bioinformatics 17: 573-4.

Mitteroecker, P. and Gunz, P. 2009. Advances in geometric morphometrics. Evol. Biol. 36: 235-47.

Neustupa, J. and Škaloud, P. 2007. Geometric morphometrics and qualitative patterns in the morphological variation of five species of Micrasterias (Zygnemophyceae, Viridiplantae). Preslia 79: 401-17.

Neustupa, J., Štastný, J. and Hodač, L. 2008. Temperaturerelated phenotypic plasticity in the green microalga Micrasterias rotata. Aquat. Microb. Ecol. 51: 77-86.

Neustupa, J., Černá, K. and Štastný, J. 2009. Diversity and morphological disparity of desmids assemblages in Central European peatlands. Hydrobiologia 630: 243-56.

Neustupa, J., Škaloud, P. and Štastný, J. 2010. The molecular phylogenetic and geometric morphometric evaluation of Micrasterias crux-melitensis/ $M$. radians species complex. J. Phycol. 46: 703-14.

Nylander, J. A. A. 2004. MrModeltest v2. Evolutionary Biology Centre, Uppsala University. Available from: http://www. abc.se/ nylander/.

Pawlowski, J., Majewski, W., Longet, D. et al. 2008. Genetic differentiation between Arctic and Antarctic monothalamous foraminiferans. Polar Biol. 31: 1205-16.

Pedersen, N. and Hedenäs, L. 2003. Phylogenetic investigations of a well supported clade within the acrocarpous moss family Bryaceae: evidence from seven chloroplast 
DNA sequences and morphology. Plant Systemat. Evol. 240: 115-32.

Playfair, G. I. 1908. Some Sydney Desmids. Proc. Linn. Soc. N. S. W. 33: 603-28.

Potapova, M. and Hamilton, P. B. 2007. Morphological and ecological variation within Achnathidium minutissimum (Bacillariophyceae) species complex. J. Phycol. 43: 56175.

Prescott, G. W., Croasdale, H. T. and Vinyard, W. C. 1977. A Synopsis of North American Desmids, Part II. Desmidiaceae: Placodermae, Section 2. University of Nebraska Press, Lincoln.

Quijano-Scheggia, S. I., Garces, E., Lundholm, N., Moestrup, O., Andree, K. and Campi, J. 2009. Morphology, physiology, molecular phylogeny and sexual compatibility of cryptic Pseudo-nitzschia delicatissima complex (Bacillariophyta), including the description of $P$. arenysensis $\mathrm{sp}$. nov. Phycologia 48: 492-509.

Rambaut, A. 2009. FigTree. Tree Figure Drawing Tool. Institute of Evolutionary Biology, University of Edinburgh. Available from: http://tree.bio.ed.ac.uk/software/figtree/.

Rhode, K. M., Pappas, J. L. and Stoermer, E. F. 2001. Quantitative analysis of shape variation in type and modern populations of Meridion (Bacillariophyceae). J. Phycol. 37: 175-183.

Rohlf, F. J. 2008. Tps series sofware. Ecology and evolution, SUNY at Stony Brook. Available from: http://life.bio. sunysb.edu/morph/.

Ronquist, F. and Huelsenbeck, J. P. 2003. MRBAYES 3: Bayesian phylogenetic inference under mixed models. Bioinformatics 19: 1572-4.
Růžička, J. 1981. Die Desmidiaceen Mitteleuropas. Band 1. 2. Lieferung. E. Schweizerbart'sche Verlagbuchhandlung (Nägele u. Obermiller), Stuttgart.

Schöniger, M. and von Haeseler, A. 1994. A stochastic model for the evolution of autocorrelated DNA sequences. Mol. Phylogenet. Evol. 3: 240-7.

Scott, A. M. and Prescott, G. W. 1958. Some freshwater algae from Arnhem land in the northern territory of Australia. Rec. Am. Aust. Sci. Exped. Arnhem. Land 3: 9-136.

Shaw, J., Lickey, E., Beck, J. T. et al. 2005. The tortoise and the hare II: relative utility of 21 noncoding chloroplast DNA sequences for phylogenetic analysis. Am. J. Bot. 92 : 142-66.

Tamura, K., Dudley, J., Nei, M. and Kumar, S. 2007. MEGA4: Molecular Evolutionary Genetics Analysis (MEGA) software version 4.0. Mol. Biol. Evol. 24: 1596-9.

Tyler, P. A. 1970. Taxonomy of Australian freshwater algae. I. The genus Micrasterias in South-Eastern Australia. Eur. J. Phycol. 5: 211-34.

Verbruggen, H. and Theriot, E. C. 2008. Building trees of algae: some advances in phylogenetic and evolutionary analysis. Eur. J. Phycol. 43: 229-52.

West, G. S. 1914. A contribution to our knowledge of the freshwater algae of Columbia. Mém. Soc. Sci. Nat. Neuchatel. 5: 1013-51.

Wolle, F. W. 1884. Desmids of the United States, and A List of American Pediastrums. Moravian Publication Office, Bethlehem.

Zelditch, M. L., Swiderski, D. L., Sheets, H. D. and Fink, W. L. 2004. Geometric Morphometrics for Biologists. A Primer. Elsevier, Boston. 